\title{
Coupled Atmosphere-Biosphere Models as a Tool for Conservation Planning and Policy
}

\author{
Richard J. Ladle ${ }^{1,2}$, Ana C. M. Malhado ${ }^{1,3}$ \& Marcos H. Costa ${ }^{3}$
}

${ }^{1}$ Instituto de Ciências Biológicas e da Saúde - ICBS, Universidade Federal de Alagoas - UFAL, Maceió, AL, Brazil

${ }^{2}$ School of Geography and the Environment, University of Oxford, South Parks Road, Oxford, United Kingdom

${ }^{3}$ Departamento de Engenharia da Agricultura, Universidade Federal de Viçosa - UFV, Viçosa, MG, Brazil

\begin{abstract}
Over the last 20 years a new generation of climate models have been developed that link atmosphere models to dynamic vegetation models (coupled atmosphere-biosphere models). These models are able to capture key feedbacks between the changing climate and changing ecosystems, providing more realistic forecasts of anthropogenic climate change. Moreover, the biosphere model can be regionally calibrated to provide more geographically specific predictions about future trajectories of environmental change over the next century. We identify four potential uses of coupled atmosphere-biosphere models for conservation: (i) more accurate and regionally specific forecasts of climate change; (ii) better understanding of carbon cycling, a key ecosystem service; (iii) better placement and design of protected areas, and; (iv) improved modeling of different land-use scenarios. Realizing these objectives will require better integration and communication between modeling and conservation communities and the development of specific visualization and planning tools that allows these complex models to be fully integrated into conservation planning.
\end{abstract}

Key words: Climate Change, Land Use, Environmental Governance, Scale, Amazon.

\section{Introduction}

The latest projections from the Intergovernmental Panel on Climate Change (IPCC) in 2007 suggest that the Earth will heat up by $1.8-4{ }^{\circ} \mathrm{C}$ this century as compared with late $20^{\text {th }}$ century baselines (IPCC 2007). The warmer temperature combined with wide-scale changes in precipitation patterns and the seasonality of weather will have a profound impact on the distribution of biomes and species. Indeed, climate is thought to play a key role in determining the distributions of species (Pearson \& Dawson 2003), and consequently there have been great efforts to predict the impacts of climate change on biodiversity. For example, one high profile study that combined a Global Circulation model (GCM) with species distribution models predicted that $15-37 \%$ of species in their sample regions would be 'committed to extinction' (living outside of their current climate envelope) as a result of climate change between 2004 and 2050 (Thomas et al. 2004).

The results of these and other studies have propelled climate change to the forefront of the global conservation agenda

\footnotetext{
${ }^{\star}$ Send correspondence to: Richard J. Ladle

Instituto de Ciências Biológicas e da Saúde - ICBS,

Universidade Federal de Alagoas - UFAL,

Praça Afrânio Jorge, s/n, Prado, CEP 57010-020,

Maceió, AL, Brasil

E-mail: richard.ladle@ouce.ox.ac.uk
}

(Jepson \& Ladle 2010), promoting a wide range of strategies for mitigation and adaptation (Hannah et al. 2002). However, conservation planning in a rapidly changing world poses considerable challenges and will require conservationists, planners and policy makers to develop flexible, dynamic approaches that seek to conserve the processes underpinning biodiversity, and not just the species that have been the traditional targets for conservation action (Fuller et al. 2011). A recent review of conservation planning studies revealed that approximately $80 \%$ of initiatives assume that neither biodiversity, nor the ecological and environmental processes on which it depends, change over time (Pressey et al. 2007).

Moreover, there is frequently a lack of alignment between spatial scale of climate change models, the key ecosystem processes that are influenced by changes in the climate, and the political and planning units that develop conservation policy and formulate responses. For example, while conservation planning is frequently done at a regional or landscape scale, the most commonly used climate change models (Global Circulation/General Climate Models) are globally calibrated and, in any case, do not incorporate the dynamic interactions between the atmosphere and the biosphere that are essential for a more complete understanding of how major ecosystems will change in a warming world. 
Over the last 20 years a new generation of climate models have been developed that seek to address these challenges by coupling GCMs to vegetation models (e.g. Cox et al. 2000, Cox et al. 2004) - hereafter referred to as coupled atmosphere-biosphere models - and, regionally calibrating the coupled models to provide more accurate and spatially specific predictions about changes in land coverage by major ecosystem types and climate change within specified regions. In the following perspective we (i) provide a brief overview of the development, characteristics and sensitivity of coupled atmosphere-biosphere models, (ii) discuss the potential application of these models to conservation policy, planning and practice and, finally, (iii) outline the various challenges faced by the modeling and conservation research communities to fully utilize and exploit the results of coupled models.

\section{Modelling Atmosphere-Biosphere Interactions}

As described above, coupled atmosphere-biosphere models have two components: a climate model linked to a vegetation model. Such a structure allows scientists to better account for the dynamic interactions between vegetation dynamics and atmospheric chemistry (e.g. carbon cycling and water cycling). The climate model part of the couple is typically a general circulation model such as the National Center for Atmospheric Research's (NCAR) Community Climate Model Version 3 (CCM3). The NCAR model is a good example of a climate model that provides a physical representation of key climate processes such as clouds and radiation, moist convection, the planetary boundary layer, and large-scale transport (Kiehl et al. 1998). The main purpose of GCMs is to model the effects of changes in certain boundary conditions (e.g. solar constant) or physical parameters (e.g. $\mathrm{CO}_{2}$ concentration) on the future global climate (McGuffie \& Henderson-Sellers 1997).

It has long been recognized that the predictions of GCMs may be compromised because they do not account for important bi-directional interactions between the atmosphere and the biosphere. In one of the first attempts to incorporate biosphere interactions into GCMs, Sellers et al. (1986) created a simple biosphere model $(\mathrm{SiB})$ that represented each terrestrial model grid area in terms of an upper and lower vegetation layer, either or both of which could be present or absent at any given location or time period. The aim was to calculate the transfer of energy, mass and momentum between the atmosphere and those parts of the earth covered in vegetation (Sellers et al. 1986). Early attempts to link biosphere and atmosphere models suffered from two shortcomings (Foley et al. 1998): they only considered the equilibrium response of vegetation to changing climatic conditions and the two models were not effectively coupled. In other words, the component models were still sufficiently independent to increase the risk of generating physical or ecological inconsistencies.
A major advance in producing a genuinely coupled model that could effectively simulate the bi-directional feedbacks between the atmosphere and the biosphere occurred in 1998 when Jonathan Foley and his colleagues developed a new framework for model integration (Foley et al. 1998). The new approach involved the common treatment of land surface, ecophysiological and vegetation dynamics processes. To demonstrate the feasibility of their integration strategy they coupled the GCM (GENESIS 2) with the Integrated Biosphere Simulator (IBIS version 1; Foley et al. 1996)- (detailed specification in Levis et al. 1999 ). Within the coupled model GENESIS simulated the atmospheric dynamics while IBIS predicted changes in vegetation dynamics in response to competition among plants and variation in $\mathrm{CO}_{2}$ levels.

The conceptual focus of studies utilizing coupled atmospherebiosphere models is extremely variable. However, the most typical uses are the generation of high-resolution maps of atmospheric CO2 (e.g. Ahmadov et al. 2007), modeling changes in vegetation cover and their dynamic relationship with climate variables such as air temperature and precipitation (e.g. Cox et al. 2004; Anav \& Mariotti 2011), predicting and monitoring changes in key ecosystem variables such as net primary production, leaf area index (e.g. Dan \& Li 2005) and carbon fluxes (e.g. Delire et al. 2003)

The wide range of uses, flexibility and predictive power of coupled models suggest that they would be useful tools (in conjunction with other climate models) for exploring and informing conservation policy. However, their utility depends, to an extent, on their robustness at different spatial scales of analysis. In this context the success of coupled models such GENESIS-IBIS in generating predictions for global land cover patterns are somewhat counterbalanced, as Foley et al. note, by "significant regional biases in the simulation" (Foley et al. 1998, p. 562). Such regional biases in estimation have continued to be an issue for coupled models. For instance, Dan et al. (2005) observed that the predicted values for leaf area index (LAI) from their coupled model (AVIM-IAP/LASG GOALS GCM) varied considerably from observed values in certain areas. Consequently, one of the goals of climate researchers over the last decade has been to produce coupled atmosphere-biosphere models that are better able to simulate regional fluxes. This is especially important from the perspective of developing effective adaptation and mitigation strategies since most political institutions are regionally situated and, furthermore, there is an increasing realization that landscape and regional scale approaches are required for effective conservation.

However, creating regionally calibrated coupled models is by no means simple and depends upon the availability of regional scale data in a form that can be assimilated into the biosphere part of the coupled model. Moreover, improved scaling between stand-level observations (e.g., flux towers) and larger scale satellite measurements also depends upon a clear understanding of the mechanisms controlling the coupled atmosphere-biosphere system (Hill et al. 2008). 
Such scaling can be achieved by comparing regional field based estimates (e.g. LAI) with remote sensing estimates (using data from moderate resolution spectroradiometer (MODIS satellites) and creating regional adjustment factors for key biophysical variables obtained from remote sensing. For example, Senna et al. (2009) regionally calibrated a coupled atmosphere-biosphere model (CCM3-IBIS) using data from four micrometeorological sites in areas of primary forest of the Large-Scale Biosphere-Atmosphere Experiment in Amazonia (LBA). The fully calibrated model was then used to investigate the impact of future climate change on ecosystem structure, dynamics, and carbon balance.

In summary, the coupling of general circulation models with biosphere models that simulate key ecosystem processes is providing increasingly sophisticated and regionally specific predictions about the future trajectory of Earth's climate and major ecosystem types. In the final sections of this article we will consider how the outputs of such models can be used to inform conservation planning and policy and the many challenges that still exist for creating meaningful synergies between modeling and conservation communities.

\section{Conservation Planning in a Changing World}

Sellers et al. (1986) identify three reasons that conservation cannot base policy on currently known patterns of biodiversity: (i) Biodiversity is generated and maintained through a variety of dynamic process, and these processes also need to be conserved; (ii) Effective conservation requires that the temporally and spatially shifting patterns of biodiversity (at all levels from genes to ecosystems) are continuously tracked; (iii) The major threats to biodiversity (e.g. habitat loss, climate change, invasive species) are dynamic, and conservation therefore requires a similarly dynamic approach to be truly effective. A necessary corollary of the above reasoning is that effective conservation planning and policy development requires tools that can rapidly and efficiently measure and monitor key ecological processes, operate on a variety of spatial and temporal scales, and realistically forecast the changes in ecosystem processes and biodiversity under different environmental change scenarios.

Coupled atmosphere-biosphere models appear to fulfill many of these criteria. First, they explicitly capture some key ecosystem processes such as primary productivity and precipitation that are known to have a major controlling influence over the generation of biodiversity at a regional scale (Whittaker et al. 2001; Willis \& Whittaker 2002). Second, they are relatively flexible and can be regionally calibrated. Finally, and perhaps most importantly, coupled models can provide detailed forecasts of the consequences of two of the greatest threats to global biodiversity, climate change and habitat transformation (natural shifts in vegetation cover due to climate change), while also providing insights into the complex, bi-directional processes that mediate the relationship between them.

Specifically, we envisage four clear applications of coupled atmosphere-biosphere models to conservation (described below). These are by no means the only possible applications, but we regard these as having the most universal scope and in most pressing need of new tools and solutions. Moreover, it is important to note that effective conservation planning will require that biosphere-atmosphere models are used along with other methods and models.

\section{Application 1 - better forecasts of climate change}

It is now extremely unlikely that climate change will be stopped, let alone reversed. This realization has led many conservation scientists to accept the inevitability of substantial ecosystem change and to plan accordingly (Jepson \& Ladle 2010). Managing the effects of climate change on the natural world is one of the biggest challenges facing global conservation, but it is a challenge with no easy solutions or quick answers.

In the most general context, the success of global conservation's fight to protect vulnerable species from the impacts of a changing climate will partly depend on the accuracy of forecasts for critical biophysical variables such as temperature, precipitation, and land cover type. By including the feedback between the atmosphere and the terrestrial ecosystems, coupled atmosphere-biosphere models have the potential to provide more realistic forecasts of a greater range of biophysical variables than general circulation models. For example, the ground-breaking study of Cox et al. (2000) demonstrated that climate vegetation feedbacks could accelerate climate change over the course of the current century. However, as with all complex models considerable uncertainties still exist, and it is important that researchers continue to combine biosphere-atmosphere models with more traditional approaches.

\section{Application 2 - carbon cycling}

The creation of an international market for trading carbon credits is one of the most promising of a number of global initiatives aimed at creating a market for ecosystem services (Jepson \& Ladle 2010). Indeed, conservation lobbyists and conservation planners are currently making huge efforts to build credibility for the Reduced Emissions for Deforestation and Degradation (REDD) mechanism which plans to provide carbon credits to developing nations in return for reducing deforestation rates.

Coupled atmosphere-biosphere models have considerable potential to contribute to this emerging field because, unlike GCMs, they simulate carbon-cycle feedbacks (Cox et al. 2000). For example, Delire et al. (2003) demonstrated that the coupled biosphere-atmosphere model, CCM3-IBIS, was 
able to robustly simulate the globally averaged carbon fluxes, zonal mean carbon fluxes, zonal mean seasonal cycle and vegetation pools with only a few regional biases. This clearly demonstrates the potential of coupled atmosphere-biosphere model to explore geographic and temporal variations in the global carbon cycle - however, integrating this type of knowledge into payment schemes for ecosystem services will be an immense challenge.

\section{Application 3 - informing decisions on the size and placement of protected areas (including areas of restricted land use or resource extraction) to most effectively mitigate against future climate change and to ensure future ecosystem functioning}

Conservationists have long been aware that climate change could have a profound effect on protected areas and there is a considerable literature addressing issues such as protected area network planning, connectivity and corridors, mobile reserves, and buffer zones (reviewed in Hannah 2008). More recently, with the increasing understanding of the bi-directional nature of climate-biosphere interactions, researchers have started to ask whether protected areas may be sufficient to prevent major shifts in climate and, by extension, further changes in land cover. The most high profile example of this is a study by Walker et al. (2009) assessing whether the Brazilian protected area system was sufficient to prevent climate tipping points in the Amazon basin causing the conversion of rainforest into semi-arid vegetation or seasonal deciduous forest. They used the Regional Atmospheric Modeling System (RAMS), a limited-area atmospheric model that uses land cover as an input, and concluded that "Amazonian dry ecosystems in the southern and southeastern basin do not desiccate appreciably and that extensive areas experience an increase in precipitation" (Walker et al. 2009 p. 1582). In other words, the current distribution of protected areas in Brazil is sufficient to prevent ecological tipping points occurring over a significant area of the Amazon.

In a clear example of how coupled models can challenge standard interpretations, Costa \& Pires (2010) used the IBIS-CCM3 model to demonstrate that deforestation in the Amazon and the Cerrado of central Brazil may influence the duration of the dry season in the arc of deforestation region of the Amazon basin. Using realistic deforestation scenarios for both biomes (cerrado + rainforest) they predicted that the dry season may increase from 5 months to 6 months in the arc of deforestation region in the first half of this century. Malhado et al. (2010) took these results and converted them into climate thresholds for major biome types using the data from Malhi et al. (2009). They concluded that there is a considerable risk that large segments of this region will cross ecological tipping points in the next 20-40 years, whatever the future governance scenario (Malhado et al. 2010).
This result provides an alternative to the more optimistic prognosis of Walker et al. (2009) and demonstrates the potential importance of coupled atmosphere-biosphere models for challenging the conclusions of more traditional modeling approaches.

\section{Application 4-modeling of 'what if' scenarios for changes in land use}

Imagined future scenarios for land use change under different environmental governance regimes have always been an essential part of conservation advocacy and are valuable tools for visualizing the consequences of different courses of action (or inaction) and informing macrogeographic conservation policy objectives. Before the advent of more sophisticated modeling techniques, such scenarios often took the form of crude extrapolations based on little or no empirical evidence. For example, Norman Myers' much used prediction of 40,000 species going extinct every year (Myers 1979) was based on crude extrapolations of tropical forest degradation and destruction and was later revealed as a conscious strategy to get extinction onto scientific and political agendas (Ladle \& Jepson 2010).

More contemporary predictions of habitat loss, transformation and species extinction are based on the latest modeling techniques and have been equally successful at gaining the attention of the international polity. Probably the most used models to simulate changes in species diversity under climate change scenarios are known as species distribution models (SDMs). The basic SDM seeks to capture the 'climate envelope' of a given species based on its current geographical distribution and then predict the geographic location of that envelope under anthropogenic climate change. If the current and future distributions are disjunct the species is said to be 'committed to extinction' As noted above, this approach has led to predictions that under "mid-range" climate change scenarios a quarter of Earth's species could be "committed to extinction" by 2050 (Thomas et al. 2004).

However, the number of steps, assumptions and choices in such models are enormous (Whittaker et al. 2005), and there is considerable need to develop a more nuanced approach to predicting the future environmental conditions that different species will experience under climate change. Once again, coupled atmosphere-biosphere models hold much promise, especially for understanding the fate of species that are restricted to specific biomes/land uses. More generally, if coupled models are proven to be more robust than uncoupled GCMs they should be more frequently used in the generation of climate scenarios for SDMs.

Coupled atmosphere-biosphere models also hold much promise in terms of more accurate modeling of land use changes under a changing climate, especially when combined with more traditional modeling methods. This may be 
especially important in the later half of the current century when global population growth is predicted to reverse and conservation may be working under reforestation and rewilding scenarios.

\section{Challenges and Conclusions}

Policy makers need the most accurate data on future climate and land use scenarios in order to make long term planning decisions. If such predictions are linked with accurate data on the current and future threat status of biomes, ecosystems and species they have a strong empirical basis for creating effective policy. Indeed, several nations have the objective of creating a single interrogable information system that has user-friendly tools that are able to link data from models (e.g. climate, SDM, socio-economic scenarios) with biodiversity data and socioeconomic data sources (Malhado \& Ladle 2010). Regionally calibrated coupled atmosphere-biosphere models may be particularly well suited for such systems because they will often be developed by regionally situated institutions and are therefore more likely to (i) align with regional conservation agendas, (ii) be responsive to regional policy requirements, (iii) be integrated into national and regional information systems (see above) and, perhaps most importantly, (iv) may have more agency with politicians and planners who work in the region in question.

Nevertheless, the integration of sophisticated and technically challenging models into conservation policy and planning faces a number of important challenges:

- Challenge 1: creating meaningful linkages between the modeling community and conservation community. At the current time climate modelers and conservationists frequently inhabit different university departments, attend different conferences and publish in different journals. There are few interdisciplinary groups or projects and funding of modeling often focuses exclusively on climate change aspects. The most obvious area for linkage is between scientists that work on species distribution models and meteorologists/ systems ecologists who are developing the latest generation of coupled models. A potentially more exciting route is to fund more interdisciplinary projects that explicitly seek to assess the conservation (and social) dimensions of coupled models;

- Challenge 2: matching the scale of analysis to the scale of conservation policy and planning decision-making. One of the most exciting aspects of coupled models is that they are able to capture changes in key ecosystem processes at the level of the biome, a natural unit for developing long term policy objectives (Riddle et al. 2011). However, although large countries such as
Brazil encompass several biomes, in smaller countries national borders are often inconvenient barriers to effective conservation planning. The results of coupled models have the potential to be more accurate at the biome-scale and could therefore encourage transborder conservation initiatives. Moreover, effective trans-border conservation will also require closer relationships between atmosphere-biosphere modelers and international conservation organizations such as Conservation international, WWF, and Birdlife International;

- Challenge 3: Even though coupled atmospherebiosphere models may give more realistic climate forecasts than uncoupled GCMs, they still have many limitations and uncertainties. The development of accurate regionally calibrated coupled atmospherebiosphere models will require greater investment in field measurements for calibrating key biophysical variables. For example, although there are, relatively speaking, a lot of micrometeorological towers in the Amazon region, there are very few towers elsewhere in South America. Moreover, more studies are needed that combine and compare the results from different climate and vegetation models in order to better understand the full range of uncertainties; and

- Challenge 4: Communication of results and uncertainties. This is a challenge for all forms of modeling, but typically, as model complexity increases so does the difficulty of communicating the sources of uncertainty and their relative importance. Recent research has shown that the academic discourse of uncertainty used by climate scientists is inappropriate when communicating with lay people and, moreover, the modeler's expertise and familiarity with the concepts and models can significantly impede their ability to communicate with people outside their own field (Pidgeon \& Fischhoff 2011).

In conclusion, coupled atmosphere-biosphere models are a powerful new tool for investigating the complex interplay between changing land-use and regional climate at a macrogeographic scale leading to forecasts that are directly applicable to conservation policy and planning at a regional and landscape scales. However, to fully exploit the potential of these models for conservation requires better linkage between the modeling and conservation community, further investment in empirical studies to improve regional calibration, further research on model sensitivity, and a greater focus on the development of tools to easily visualize and compare/overlay the model forecasts with conservation and socioeconomic data. 


\section{References}

Ahmadov R et al., 2007. Mesoscale covariance of transport and CO2 fluxes: Evidence from observations and simulations using the WRF-VPRM coupled atmosphere-biosphere model. Journal of Geophysical Research-Atmospheres, 112. http://dx.doi.org/10.1029/2007JD008552

Anav A \& Mariotti A, 2011. Sensitivity of natural vegetation to climate change in the Euro-Mediterranean area. Climate Research, 46:277-292. http://dx.doi.org/10.3354/cr00993

Costa MH \& Pires GF, 2010. Effects of Amazon and Central Brazil deforestation scenarios on the duration of the dry season in the arc of deforestation. International Journal of Climatology, 30:1970-1979. http://dx.doi.org/10.1002/ joc. 2048

Cox PM et al., 2000. Acceleration of global warming due to carbon-cycle feedbacks in a coupled climate model. Nature, 408:184-187. PMid:11089968. http://dx.doi. org/10.1038/35041539

Cox PM et al., 2004. Amazonian forest dieback under climatecarbon cycle projections for the 21 st century. Theoretical and Applied Climatology, 78:137-156. http://dx.doi.org/10.1007/ s00704-004-0049-4

Dan L, Ji JJ \& Li YP, 2005. Climatic and biological simulations in a two-way coupled atmosphere-biosphere model (CABM). Global and Planetary Change, 47:153-169.

Delire C, Foley JA \& Thompson S, 2003. Evaluating the carbon cycle of a coupled atmosphere-biosphere model. Global Biogeochemical Cycles, 17(1012). http://dx.doi. org/10.1029/2002GB001870

Foley JA et al., 1996. An integrated biosphere model of land surface processes, terrestrial carbon balance, and vegetation dynamics. Global Biogeochemical Cycles, 10:603-628. http:// dx.doi.org/10.1029/96GB02692

Foley JA et al., 1998. Coupling dynamic models of climate and vegetation. Global Change Biology, 4:561-579. http://dx.doi. org/10.1046/j.1365-2486.1998.t01-1-00168.x

Fuller RA et al., 2011. Planning for persistence in a changing world. In Ladle RJ \& Whittaker RJ (eds.), Conservation Biogeography. London: John Wiley \& Sons, Ltd. p. 161-189. http://dx.doi.org/10.1002/9781444390001.ch7

Hannah L, Midgley GF \& Millar D, 2002. Climate change-integrated conservation strategies. Global Ecology and Biogeography, 11:485-495. http://dx.doi. org/10.1046/j.1466-822X.2002.00306.x

Hannah L, 2008. Protected areas and climate change. Annals of the New York Academy of Sciences, 1134:201-212. PMid:18566095. http://dx.doi.org/10.1196/annals.1439.009

Hill TC, Williams M \& Moncrieff JB, 2008. Modeling feedbacks between a boreal forest and the planetary boundary layer. Journal of Geophysical Research-Atmospheres, 113(D15122). http://dx.doi.org/10.1029/2007JD009412

Intergovernmental Panel on Climate Change - IPCC, 2007. Climate Change 2007: Impacts, adaptation and vulnerability, Summary for Policymakers. Cambridge: Cambridge University Press.

Jepson P \& Ladle RJ, 2010. Conservation: A Beginner's Guide. Oxford: One World.
Kiehl JT et al., 1998. The National Center for Atmospheric Research Community Climate Model: CCM3. Journal of Climate, 11:1131-1149. http://dx.doi. org/10.1175/1520-0442(1998)011\%3C1131:TNCFAR\% 3E2.0.CO;2

Ladle RJ \& Jepson P, 2010. Origins, agency and alignment of extinction rhetoric. Environment \& Society: Advances in Research, 1:96-115.

Levis S, Foley JA \& Pollard D, 1999. Potential high latitude vegetation feedbacks on $\mathrm{CO} 2$ induced climate change. Geophysical Research Letters, 26:747-750. http://dx.doi. org/10.1029/1999GL900107

Malhado ACM \& Ladle RJ, 2010. New data system to galvanize Brazil's conservation efforts. Nature, 465:869869. PMid:20559367. http://dx.doi.org/10.1038/465869a

Malhado ACM, Pires GF \& Costa MH, 2010. Cerrado conservation is essential to protect the Amazon rainforest. Ambio, 39:580-584. PMid:21141777. http://dx.doi. org/10.1007/s13280-010-0084-6

Malhi Y et al., 2009. Exploring the likelihood and mechanism of a climate-change-induced dieback of the Amazon rainforest. Proceedings of the National Academy of Sciences of the USA, 106:20610-20615. PMid:19218454. PMCid:2791614. http:// dx.doi.org/10.1073/pnas.0804619106

Mcguffie K \& Henderson-Sellers A, 1997. A Climate modelling primer. London: John Wiley \& Sons, Ltd.

Myers N, 1979. The sinking ark: a new look at the problem of disappearing species. Oxford: Reader's Digest Young Families.

Pearson RG \& Dawson TP, 2003. Predicting the impacts of climate change on the distribution of species: are bioclimate envelope models useful? Global Ecology and Biogeography, 12:361-371. http://dx.doi.org/10.1046/j.1466-822X.2003.00042.x

Pidgeon N \& Fischhoff B, 2011. The role of social and decision sciences in communicating uncertain climate risks. Nature Climate Change, 1:35-41. http://dx.doi.org/10.1038/ nclimate 1080

Pressey RL et al., 2007. Conservation planning in a changing world. Trends in Ecology \& Evolution, 22:583-592. http:// dx.doi.org/10.1016/j.tree.2007.10.001

Riddle BR et al., 2011. Basic biogeography: estimating biodiversity and mapping nature. In Ladle RJ \& Whittaker RJ (eds.). Conservation Biogeography. Oxford: John Wiley \& Sons, Ltd. p. 45-92. http://dx.doi.org/10.1002/9781444390001.ch4

Sellers PJ et al., 1986. A simple biosphere model (SIB) for use within general-circulation models. Journal of the Atmospheric Sciences, 43:505-531. http://dx.doi. org/10.1175/1520-0469(1986)043\%3C0505:ASBMFU\% 3E2.0.CO;2

Senna MCA et al., 2009. Vegetation structure and dynamics in Amazonia using a coupled climate-biosphere model. Earth Interactions, 13(11):1-28. http://dx.doi. org/10.1175/2009ei1281.1171

Thomas CD et al., 2004. Extinction risk from climate change. Nature, 427:145-148. PMid:14712274. http://dx.doi. org/10.1038/nature02121

Walker R et al., 2009. Protecting the Amazon with protected areas. Proceedings of the National Academy of Sciences of the 
USA, 106:10582-10586. PMid:19549819. PMCid:2705550. http://dx.doi.org/10.1073/pnas.0806059106

Whittaker RJ, Willis KJ \& Field R, 2001. Scale and species richness: towards a general, hierarchical theory of species diversity. Journal of Biogeography, 28:453-470. http://dx.doi. org/10.1046/j.1365-2699.2001.00563.x
Whittaker RJ et al., 2005. Conservation Biogeography: assessment and prospect. Diversity and Distribution, 11:3-23. http:// dx.doi.org/10.1111/j.1366-9516.2005.00143.x

Willis KJ \& Whittaker RJ, 2002. Ecology - species diversity - scale matters. Science, 295:1245-1248. PMid:11847328. http:// dx.doi.org/10.1126/science.1067335

Received: July 2011

First Decision: September 2011 Accepted: September 2011 